\title{
Synthesis, characterization and corrosion inhibition study of 2-( $\alpha$-hydroxyethyl)benzimidazole: A green corrosion inhibitor
}

\author{
M. Obulichetty ${ }^{1}$, D. Saravanabharathi ${ }^{2}$ and S.Rameshkumar ${ }^{3}$ \\ \{mos.as@psgtech.ac.in ${ }^{1}$,dsb.chem@psgtech.ac.in ${ }^{2}$, srksvc2016@gmail.com ${ }^{3}$ \} \\ Department of Applied Science, PSG College of Technology, Coimbatore - 641 004, India. ${ }^{1}$, \\ Department of Chemistry, PSG College of Technology, Coimbatore -641004 , India. ${ }^{2}$, Department of \\ Chemistry, Sri Vasavi College, Erode $-638316^{3}$
}

\begin{abstract}
A green corrosion inhibitor 2-( $\alpha$-hydroxyethyl)benzimidazole was synthesized via the reaction between ortho phenylene diamine and DL-lactic acid in aqueous solution. The as-synthesized compound was crystallized using methanol and characterized by melting point analysis, proton nuclear magnetic resonance (PMR) and Fourier transform infrared (FTIR) spectroscopy. A weight loss method was used to evaluate the corrosion inhibition property of 2-( $\alpha$-hydroxyethyl)benzimidazole on mild steel corrosion in $1.0 \mathrm{M}$ $\mathrm{HCl}$ solution. The corrosion inhibition study reveals that, the synthesized and recrystallized product acts as good corrosion inhibitor.
\end{abstract}

Keywords: Green Corrosion, Magnetic Resonance, Benzimidazole

\section{Introduction}

In recent decades, the research is more focused towards the development of the "new green corrosion inhibitors", which exhibit better inhibition property with lesser environmental problems [1-5]. The compounds such as flavonoids, alkaloids and other natural products as well as synthetic organic compounds with negligible toxicity are considered and used as an organic green corrosion inhibitors $[6,7]$. A thorough review of literature revealed that the locally available plant extracts, substances from renewable sources and synthetic organic compounds (Schiff base, drugs) were used as corrosion inhibitors and are also classified as eco-friendly materials or green inhibitors [8-11]. For example, the ethanol extraction of banana peels (M.Sapientum) is used as inhibitor to prevent corrosion of mild steel [12, 13]. Okafor et al., examined the corrosion inhibition efficiency of onions extracts on various metals and alloys [14].

Numerous studies have been published in connection with inhibition of corrosion on various metals in different corrosive conditions. Initially, the focus was on $\mathrm{N}$ - atom containing organic compounds, owing to their ability to prevent the corrosion of metals and alloys [1519].

Benzimidazole and its derivatives are a crucial class of organic compounds which are mainly used in the field of clinical pharmacology, benzimidazoles also have a prominent place in organo catalysis, organometallic and materials chemistry [20]. Thorough literature studies suggest that a good number of benzimidazole and its derivatives were found application in 
corrosion inhibition owing to the nature of imidazole groups [21-24]. The imidazole groups are effective metal ion binding sites in biological systems.

The literature survey clearly implies that benzimidazole and its derivatives act as promising candidates for inhibition of corrosion on various metals [22, 23]. To the best of our knowledge, corrosion inhibition efficiency of the 2-( $\alpha$-hydroxyethyl)benzimidazole has not been performed. Therefore, present work is intended to synthesize the 2-( $\alpha$ hydroxyethyl)benzimidazole and study its corrosion inhibition performance on the mild steel in hydrochloric acid medium.

\section{Experimental section}

\subsection{Materials and Methods}

Chemicals employed in the present work o-phenylene diamine (C6H8N2), DL-lactic acid $(\mathrm{C} 3 \mathrm{H} 6 \mathrm{O} 3)$ and anhydrous sodium carbonate $(\mathrm{Na} 2 \mathrm{CO} 3)$ are of $\mathrm{AR}$ grade and purchased from Merk. The chemicals and solvent methanol were used without any further purification. Analytical grade reagent $\mathrm{HCl}$ and doubly distilled water were used for the preparation of 4.0 $\mathrm{M}$ and $1.0 \mathrm{M} \mathrm{HCl}$ solutions.

\subsection{Synthesis of 2-( $\alpha$-hydroxyethyl)benzimidazole}

Titled compound was synthesized by refluxing o-phenylene diamine $(0.1 \mathrm{~mol}, 10.8 \mathrm{~g})$ with DL-lactic acid $(0.22 \mathrm{~mol}, 17 \mathrm{~mL})$ in presence $30 \mathrm{~mL}$ of $4.0 \mathrm{M} \mathrm{HCl}$ acid solution under Phillips condition [25]. The reaction scheme for synthesis of the compound is mentioned in Figure.2.1.

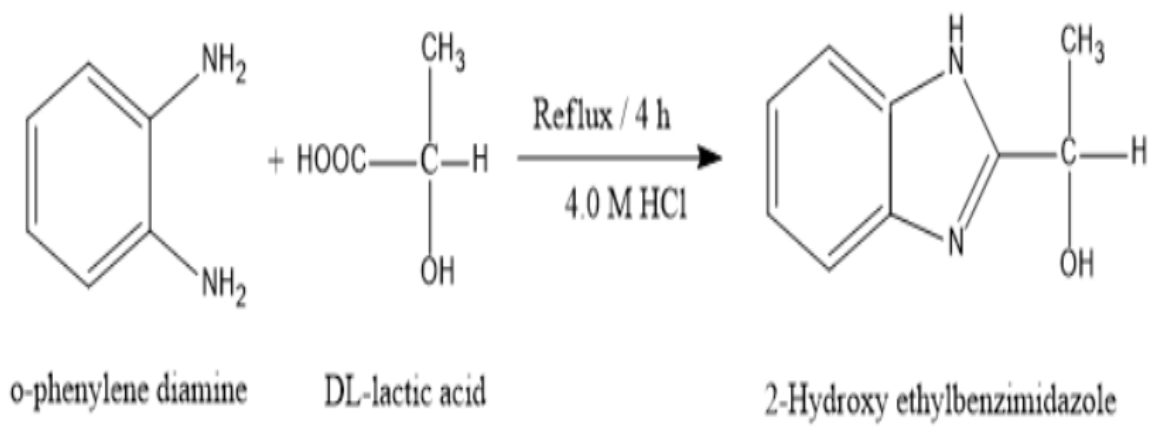

Fig.2.1Scheme for synthesis of 2-( $\alpha$-hydroxyethyl)benzimidazole

A light pink colored microcrystalline product obtained was thoroughly washed with ice cold water in order to avoid the contamination of the unreacted precursors. Synthesised product was dried in atmospheric condition for about 48 hours. The dried compound, recrystallised from methanol, gave pure white crystalline product. As synthesized and recrystallized product are shown in the Figure 2.2. 

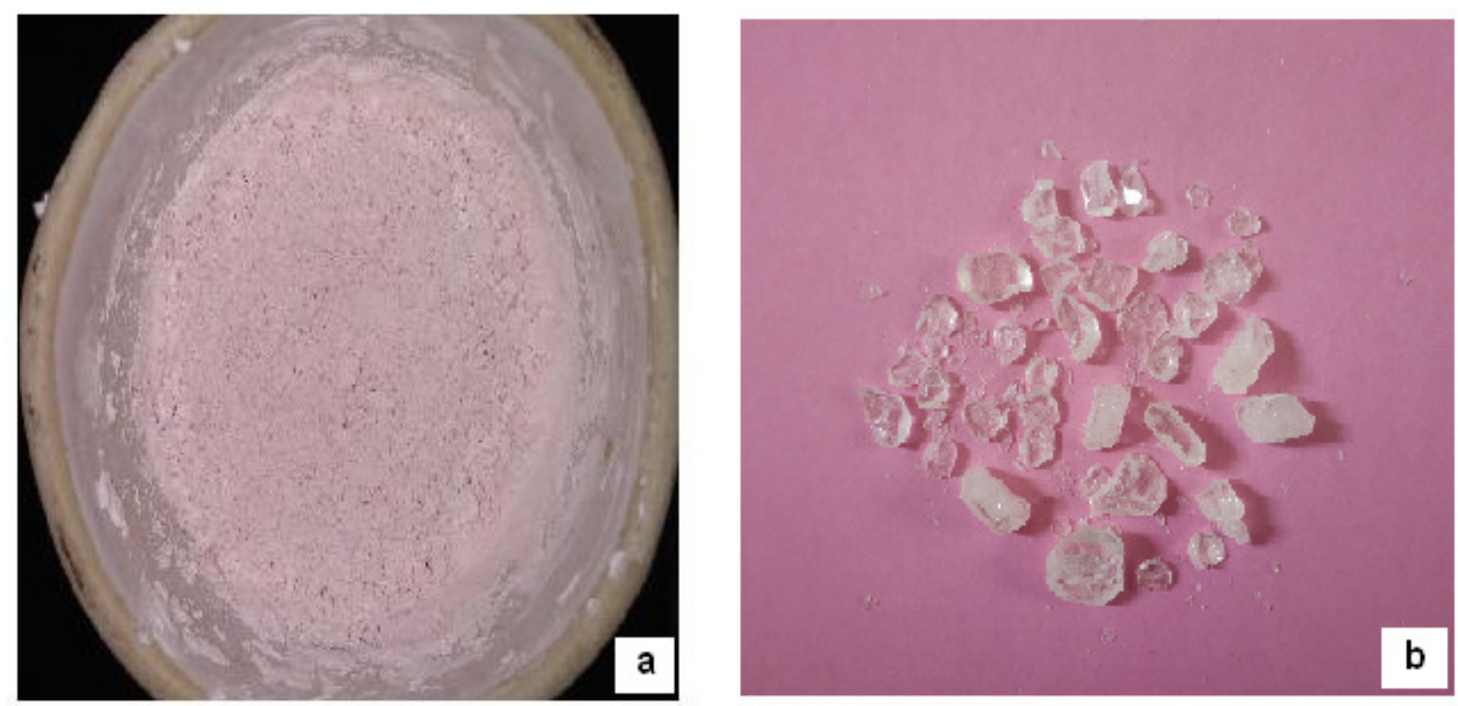

Fig.2.2. (a) As -synthesised and

(b) Re-crystallized product in methanol

The recrystallised compound was characterized as follows:

Open capillary tubes were used to determine the melting points of the products, and they are uncorrected.

In order to record FTIR spectrum, a $\mathrm{KBr}$ pellet technique was used, wherein, 5-10 mg of recrystallised product was thoroughly grounded with $100 \mathrm{mg}$ of solid $\mathrm{KBr}$.The resulting solid mixture was compressed by giving an appropriate pressure to form a thin transparent pellet. The FTIR spectral analysis of powdered and pelletized sample was recorded in region of 4000 to $400 \mathrm{~cm}^{-1}$. TheFTIR measurements of the sample were recorded using Shimadzu 8400S FTIR spectrophotometer.

${ }^{1} \mathrm{H}$ NMR spectra were recorded on a AV400-Bruker $400 \mathrm{MHz}$ High resolution multinuclear FTNMR spectrometer using acetone- $\mathrm{d}_{6}$ as a solvent.

The inhibition efficiency of the recrystallized product were evaluated using weight loss method on mild steel plates having the dimensions $(5.08 \mathrm{~cm} \mathrm{x} 2.54 \mathrm{~cm})$, with exposed total area of $25.80 \mathrm{~cm}^{2}$ was used. Different concentrations of synthesized product $(250,500,750$, 1000 and $1250 \mathrm{ppm}$ ) in $1.0 \mathrm{M} \mathrm{HCl}$ aqueous solution was prepared. The weighed mild steel plates are immersed in the corrosive medium for 60 minutes. The different in weight before and after exposure to corrosive medium is recorded after washed with double distilled and dried in air. Corrosion rate and inhibitor efficiency calculated using the following equations: 


\begin{tabular}{|l|l|}
$\begin{array}{l}\text { Corrosion rate }=\frac{534\left(W_{1}-W_{2}\right)}{D A T} \\
\text { where, }\end{array}$ & $\begin{array}{l}\text { Inhibitor efficiency }=\frac{A-B}{A} \times 100 \\
\text { where, }\end{array}$ \\
$\mathrm{W}_{1}=$ Weight of the specimen before & $\mathrm{A}=$ Corrosion rate of the specimen in the \\
exposure to corrosive medium & $\begin{array}{l}\text { absence of inhibitor. } \\
\mathrm{W}_{2}=\text { Weight of the specimen after } \\
\text { B = Corrosion rate of the specimen in the } \\
\text { exposure to corrosive medium } \\
\mathrm{D}=\text { Density of mild steel }\left(7.8 \mathrm{~g} / \mathrm{cm}^{3}\right)\end{array}$ \\
$\mathrm{A}=$ Exposed area of the plate in square & \\
inches. & \\
$\mathrm{T}=$ Duration of exposure to corrosive \\
media in hours.
\end{tabular}

\section{Results and Discussion:}

\subsection{Melting point determination}

Re-crystallized sample is powdered well, taken in a capillary tube and inserted into the melting point apparatus and subjected to heating from room temperature to $190^{\circ} \mathrm{C}$. The sample has melted sharplyat $179^{\circ} \mathrm{C}$. The identified melting point is well matching with the already reported value in the literature [25], which confirms the purity of the recrystallised sample.

\subsection{FTIR analysis}

The FTIR spectrum was taken in order to confirm structural features of the synthesized compound. The FTIR spectrum of the recrystallised sample is shown in the Fig 3.1.

The broad absorption band at $2600-3400 \mathrm{~cm}^{-1}$ is confirm the presence of $-\mathrm{O}-\mathrm{H}$ and $\mathrm{N}-\mathrm{H}$ stretching. Aromatic and aliphatic $\mathrm{C}-\mathrm{H}$ stretching are responsible for the strong and sharp absorption bands at $3178 \mathrm{~cm}^{-1}$ and $2922 \mathrm{~cm}^{-1}$, respectively. The absorption band at $1624 \mathrm{~cm}^{-1}$ is due to $\mathrm{C}=\mathrm{N}$ stretching. The IR spectrum reveals that, 2- $(\alpha-$ hydroxyethyl)benzimidazole molecular structure contains $-\mathrm{OH},-\mathrm{N}-\mathrm{H},-\mathrm{C}-\mathrm{H},-\mathrm{C}=\mathrm{N}-,-\mathrm{C}=\mathrm{C}-$ and $-\mathrm{C}-\mathrm{N}$ - functional groups/backbone. 


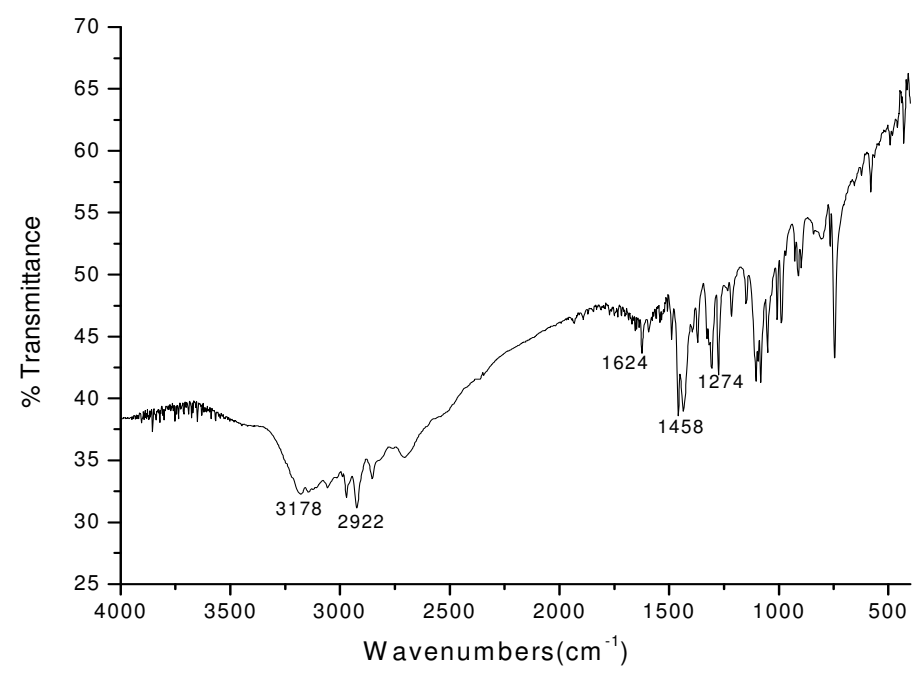

Fig.3.1FT-IR profile of 2-( $\alpha$-hydroxyethyl)benzimidazole.

\subsection{FT-NMR Analysis}

The $\mathrm{H}^{1}$ NMR profile of recrystallised sample is presented in the Figure.3.2. The integrated spectra are shown in the Figure.3.3 and 3.4.
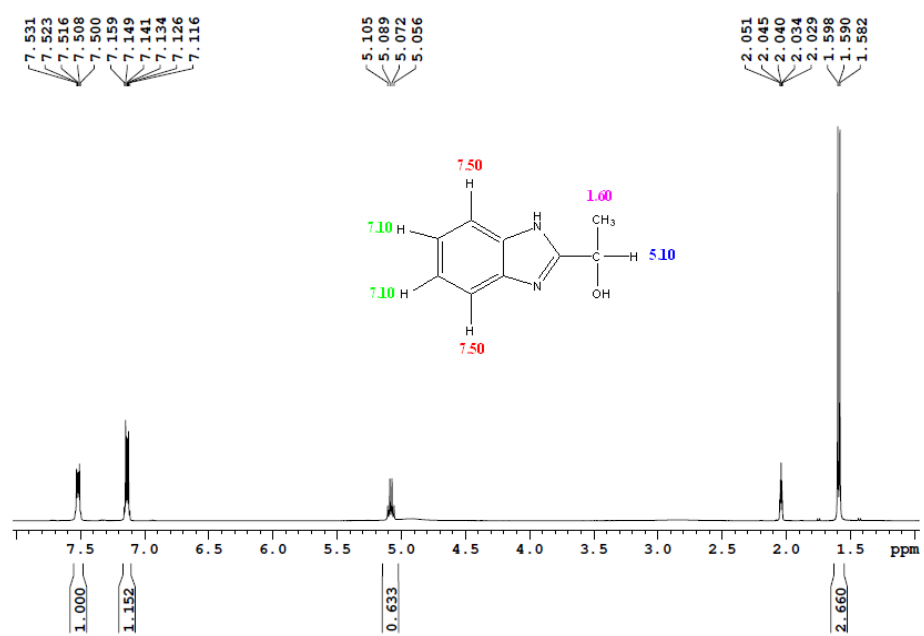

Fig.3.2 FTNMR spectrum of 2-( $\alpha$-hydroxyethyl)benzimidazole in acetone $\mathrm{d}_{6}$. 


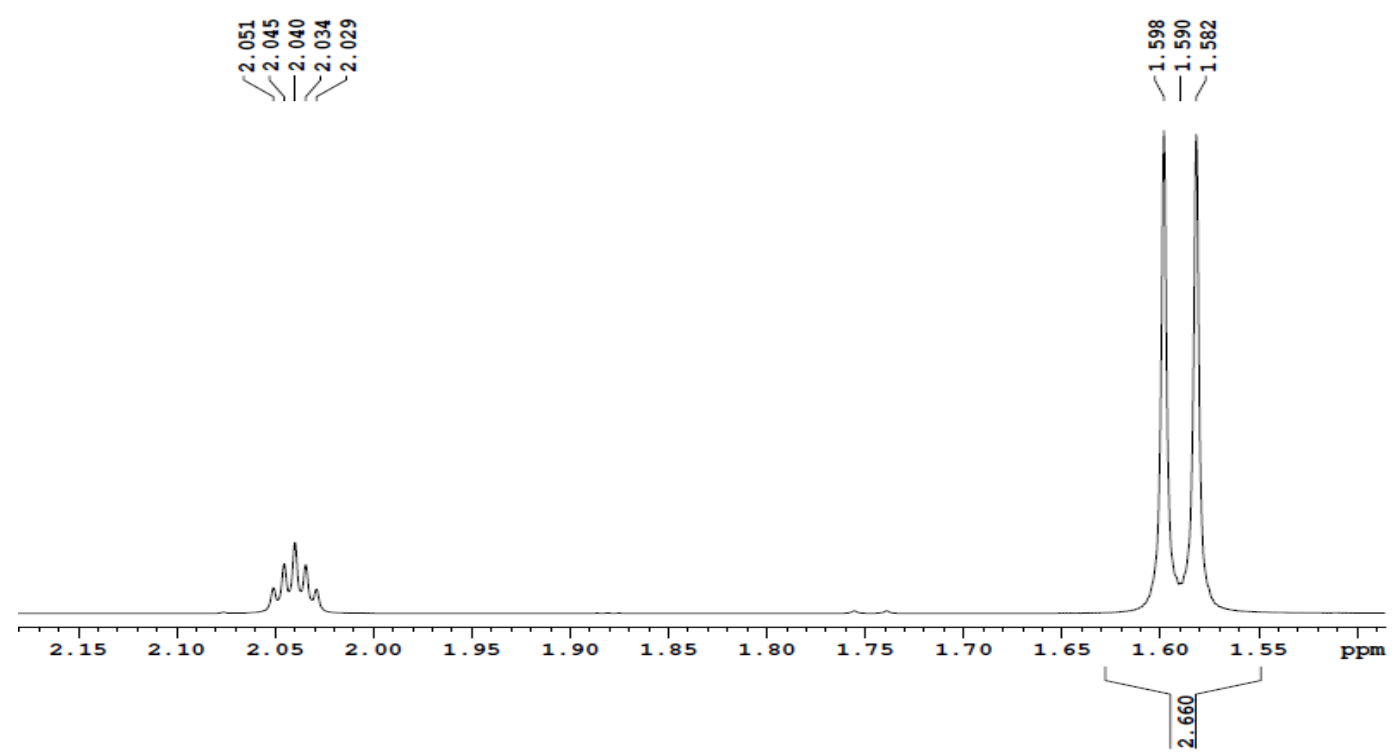

Fig.3.3 Spin-spin splitting pattern of methyl protons of 2-( $\alpha$-hydroxyethyl)benzimidazole and

solvent acetone- $\mathrm{d}_{6}$.

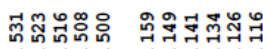

initiving

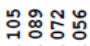

ining

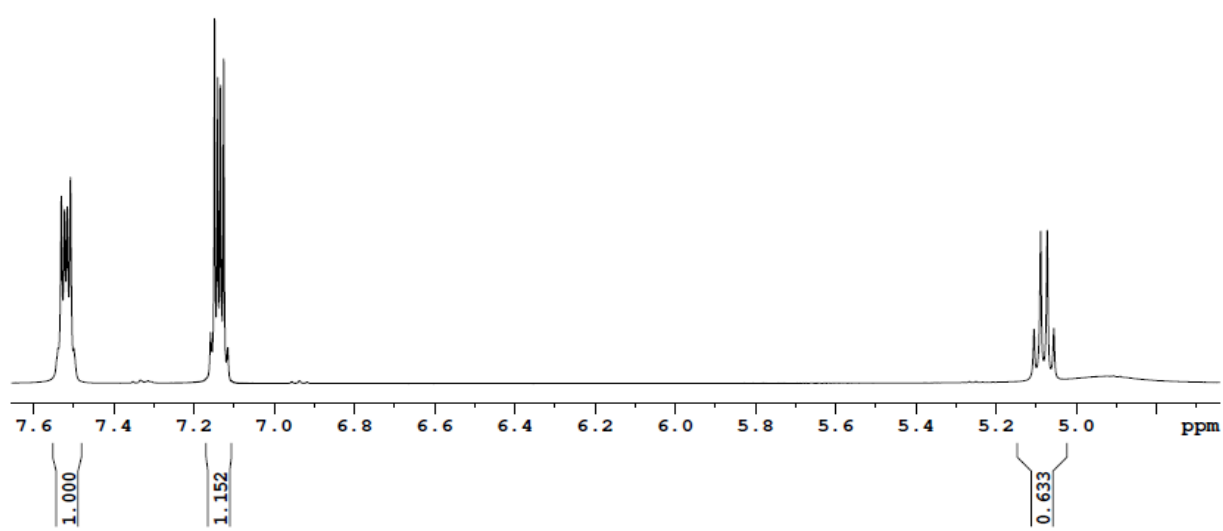

Fig3.4Spin-spin splitting pattern of methyl and aromatic protons of

2-( $\alpha$-hydroxyethyl)benzimidazole. 
The $\mathrm{H}^{1}$ NMR spectra of 2-( $\alpha$-hydroxyethyl)benzimidazole showed a doublet at $\delta=$ $1.60 \mathrm{ppm}$ and quartet at $\delta=5.10 \mathrm{ppm}$ which is due to methyl $\left(-\mathrm{CH}_{3}\right)$ and methine $(-\mathrm{CH})$ protons. The presence of multiplet at $\delta=7.10 \mathrm{ppm}$ and $\delta=7.50 \mathrm{ppm}$ is due to chemically non-equivalent aromatic ring protons. The quintet peak at $\delta=2.05 \mathrm{ppm}$ is due to the solvent acetone- $\mathrm{d}_{6}$. The integrated intensities of each signal in the ${ }^{1} \mathrm{H}$ NMR spectra are well correlated with the distinct types of protons present in the synthesized product.

\subsection{Evaluation of inhibitor efficiency by weight loss method}

In the present investigation, 250, 500, 750, 1000 and $1250 \mathrm{ppm}$ concentrations of inhibitors solutions were prepared using $1.0 \mathrm{M} \mathrm{HCl}$. The inhibition efficiency of the crystallized product was evaluated after one hour immersion of pretreated mild steel incorrosive media as mentioned in the literature [26]. The experimental set up for corrosion inhibition study is shown in Figure.3.5.

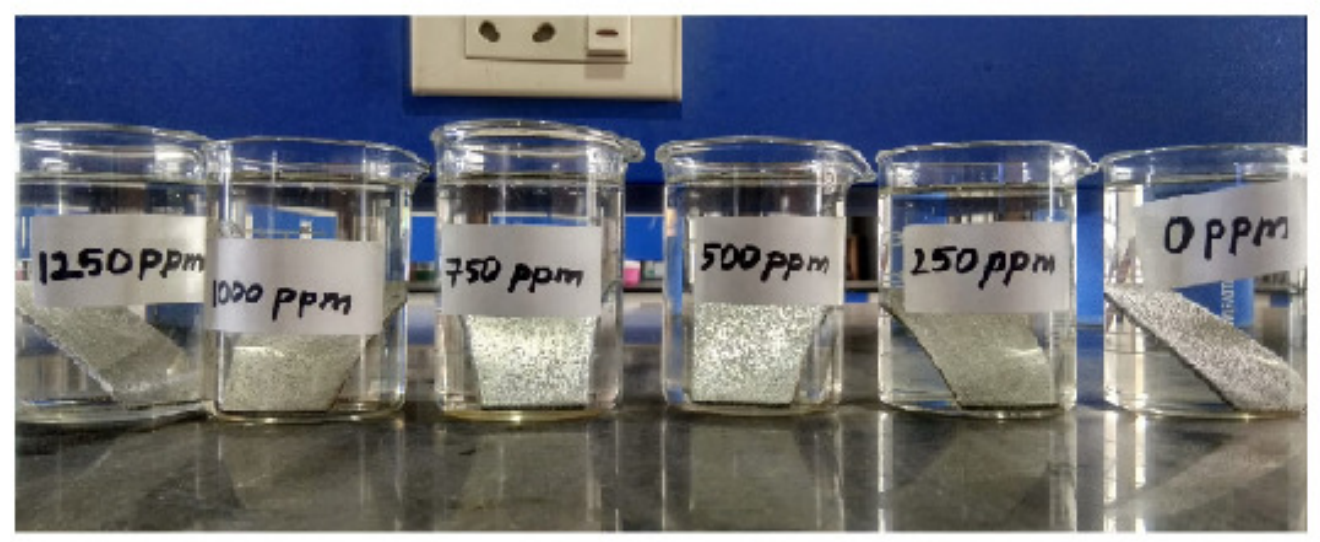

Fig.3.5 Experimental arrangement for corrosion inhibition study

The experimental observations of the gravimetric method for synthesized compound are presented in the Table.3.1.

Table.3.1 Weight loss data of mild steel in $1.0 \mathrm{M} \mathrm{HCl}$

\begin{tabular}{|c|c|c|}
\hline $\begin{array}{c}\text { Concentration of } \\
\text { inhibitor } \\
\text { (ppm) }\end{array}$ & Weight loss (mg) & $\begin{array}{c}\text { Inhibitor efficiency } \\
\text { (\%) }\end{array}$ \\
\hline 0 & 33.6 & - \\
\hline 250 & 26.0 & 22.6 \\
\hline
\end{tabular}




\begin{tabular}{|c|c|c|}
\hline 500 & 23.7 & 29.4 \\
\hline 750 & 20.4 & 39.2 \\
\hline 1000 & 20.1 & 40.1 \\
\hline 1250 & 18.1 & 46.1 \\
\hline
\end{tabular}

The above table 3.1 clearly suggest that, the corrosion resistance of the synthesized compound in $1.0 \mathrm{M} \mathrm{HCl}$ solution increased with the concentration (i.e. $250 \mathrm{ppm}-1250 \mathrm{ppm}$ ) due to the number of inhibitor molecules get adsorbed onto the mild steel substrate increased, which separates the substrate material from the corrosive medium[27]. On the other hand, the substrate material is fully exposed to the corrosive medium due to the absence of inhibitor molecules and dissolution of metal is relatively high.

\section{Conclusion}

In conclusion, we synthesized 2-( $\alpha$-hydroxyethyl)benzimidazole from o-phenylene diamine and DL-lactic acid in the presence of $4.0 \mathrm{M} \mathrm{HCl}$ using Phillips method and recrystallized using methanol. The crystals are found to be transparent and colorless. Recrystallised sample shown a sharp melting point at $179 \square \mathrm{C}$, which confirmed the purity of the crystals. Presence of various functional groups was ascertained from FTIR analysis. The different chemical environment of the protons in the molecular structure was confirmed by ${ }^{1} \mathrm{H}$ NMR spectral analysis. The spectral data FTIR, and ${ }^{1} \mathrm{H}$ NMR of the synthesized compound are in full agreement with the proposed structures.The gravimetric method adopted to determine the corrosion efficiency of the synthesized compound reveals that, the 2-( $\alpha-$ hydroxyethyl)benzimidazole is a potential candidate to act as a corrosion inhibitor for mild steel in $1.0 \mathrm{M} \mathrm{HCl}$ solution. Moreover, synthesised compound is environmentally friendly and it can be considered as green corrosion inhibitor.

\section{References}

[1] Farhadian A, Rahimi A, Safaei N, Shaabani A, Abdouss M, Alavi A. A theoretical and experimental study of castor oil-based inhibitor for corrosion inhibition of mild steel in acidic medium at elevated temperatures. Corrosion Science. 2020 Oct 1;175:108871. 
[2] Verma C, Alrefaee SH, Quraishi MA, Ebenso EE, Hussain CM. Recent developments in sustainable corrosion inhibition using ionic liquids: A review. Journal of Molecular Liquids. 2021 Jan 1;321:114484.

[3] Khaled KF. Guanidine derivative as a new corrosion inhibitor for copper in $3 \% \mathrm{NaCl}$ solution. Materials Chemistry and Physics. 2008 Nov 15;112(1):104-11.

[4] Dahmani K, Galai M, Ouakki M, Cherkaoui M, Touir R, Erkan SU, Kaya S, El Ibrahimi B. Quantum chemical and molecular dynamic simulation studies for the identification of the extracted cinnamon essential oil constituent responsible for copper corrosion inhibition in acidified $3.0 \mathrm{wt} \% \mathrm{NaCl}$ medium. Inorganic Chemistry Communications. $2021 \mathrm{Feb}$ 1;124:108409.

[5] Zunita M, Wahyuningrum D, Bundjali B, Wenten IG, Boopathy R. Corrosion Inhibition Performances of Imidazole Derivatives-Based New Ionic Liquids on Carbon Steel in Brackish Water. Applied Sciences. 2020 Jan;10(20):7069.

[6] Marzorati S, Verotta L, Trasatti SP. Green corrosion inhibitors from natural sources and biomass wastes. Molecules. 2019 Jan;24(1):48.

[7] Grassino AN, Cindrić I, Halambek J. Green Corrosion Inhibitors from Biomass and Natural Sources. Sustainable Corrosion Inhibitors. 2021 Aug 5;107:46.

[8] Wei H, Heidarshenas B, Zhou L, Hussain G, Li Q, Ostrikov KK. Green inhibitors for steel corrosion in acidic environment: state of art. Materials Today Sustainability. 2020 Dec $1 ; 10: 100044$.

[9] Miralrio A, Espinoza Vázquez A. Plant extracts as green corrosion inhibitors for different metal surfaces and corrosive media: A review. Processes. 2020 Aug;8(8):942.

[10] .Dehghani A, Bahlakeh G, Ramezanzadeh B, Ramezanzadeh M. Detailed macro-/micro-scale exploration of the excellent active corrosion inhibition of a novel environmentally friendly green inhibitor for carbon steel in acidic environments. Journal of the Taiwan Institute of Chemical Engineers. 2019 Jul 1;100:239-61.

[11] Fernandes CM, Fagundes TD, dos Santos NE, Rocha TS, Garrett R, Borges RM, Muricy G, Valverde AL, Ponzio EA. Irciniastrobilina crude extract as corrosion inhibitor for mild steel in acid medium. Electrochimica Acta. 2019 Jul 20;312:137-48.

[12] Africa S. Adsorption and inhibitive properties of ethanol extracts of Musa sapientum peels as a green corrosion inhibitor for mild steel in H2SO4. African Journal of Pure and Applied Chemistry. 2008 Jun;2(6):046-54.

[13] Asif m, kaur a. Biologically active phytochemical contents and biological activities of whole musa acuminata (banana) plant. International journal of recent advances in medical \& pharma research. 2018;1(1).

[14] Okafor PC, Ikpi ME, Uwah IE, Ebenso EE, Ekpe UJ, Umoren SA. Inhibitory action of Phyllanthus amarus extracts on the corrosion of mild steel in acidic media. Corrosion Science. 2008 Aug 1;50(8):2310-7.

[15] El Ibrahimi B, Guo L. Azole-based compounds as corrosion inhibitors for metallic materials. InAzoles-Synthesis, Properties, Applications and Perspectives $2020 \mathrm{Jul}$ 2. IntechOpen.

[16] Loto CA, Loto RT, Popoola AP. Corrosion inhibition of thiourea and thiadiazole derivatives: a review. Journal of Materials and Environmental Science. 2012 Jun 11;3(5):885-94.

[17] Ju H, Kai ZP, Li Y. Aminic nitrogen-bearing polydentate Schiff base compounds as corrosion inhibitors for iron in acidic media: a quantum chemical calculation. Corrosion Science. 2008 Mar 1;50(3):865-71

[18] Fouda AS, Aggour Y, Bekheit G, Ismail MA. Moringa oleifera extract as green corrosion inhibitor for zinc in polluted sodium chloride solutions. International Journal of Advanced Research. 2014;2:1158-70.

[19] Abboud Y, Abourriche A, Saffaj T, Berrada M, Charrouf M, Bennamara A, Cherqaoui A, Takky D. The inhibition of mild steel corrosion in acidic medium by 2, 2'-bis (benzimidazole). Applied surface science. 2006 Sep 30;252(23):8178-84.

[20] Chao, S.T.H., 2008. Designer benzimidazoles: Synthesis, characterization, and applications (Doctoral dissertation). 
[21] Gutiérrez E, Rodríguez JA, Cruz-Borbolla J, Alvarado-Rodríguez JG, Thangarasu P. Development of a predictive model for corrosion inhibition of carbon steel by imidazole and benzimidazole derivatives. Corrosion Science. 2016 Jul 1;108:23-35.

[22] Moreira RR, Soares TF, Ribeiro J. Electrochemical investigation of corrosion on AISI 316 stainless steel and AISI 1010 carbon steel: study of the behaviour of imidazole and benzimidazole as corrosion inhibitors. Advances in Chemical Engineering and Science. 2014 Sep 17;4(04):503.

[23] Purwoko AA. Theoretical study of the substituent effect on corrosion inhibition performance of benzimidazole and its derivatives. International Journal of Corrosion and Inhibition Scale. 2019;8(3):673-88.

[24] Dutta A, Saha SK, Adhikari U, Banerjee P, Sukul D. Effect of substitution on corrosion inhibition properties of 2-(substituted phenyl) benzimidazole derivatives on mild steel in $1 \mathrm{M}$ $\mathrm{HCl}$ solution: a combined experimental and theoretical approach. Corrosion Science. $2017 \mathrm{Jul}$ 15;123:256-66.

[25] D.S. Vijayan, A. Mohan, J. Revathy, D. Parthiban, R. Varatharajan, "Evaluation of the impact of thermal performance on various building bricks and blocks: A review", Environmental Technology \& Innovation 23 (2021) 101577, https://doi.org/10.1016/j.eti.2021.101577.

[26] Maayta, A.K. and Al-Rawashdeh, N.A.F., 2004. Inhibition of acidic corrosion of pure aluminum by some organic compounds. Corrosion science, 46(5), pp.1129-1140.

[27] Ouici H, Tourabi M, Benali O, Selles C, Jama C, Zarrouk A, Bentiss F. Adsorption and corrosion inhibition properties of 5-amino 1,3, 4-thiadiazole-2-thiol on the mild steel in hydrochloric acid medium: Thermodynamic, surface and electrochemical studies. Journal of Electroanalytical Chemistry. 2017 Oct 15; 803:125-34. 